\title{
Allopurinol use and prevention of gout attack
}

\author{
Shih-Wei Lai ${ }^{1,2,3}$ (D) Yu-Hung Kuo ${ }^{4}$ Kuan-Fu Liao ${ }^{3,5}$ \\ Received: 28 May 2020 / Accepted: 11 August 2020 / Published online: 15 August 2020 \\ (C) Springer-Verlag GmbH Germany, part of Springer Nature 2020
}

One review article written by Hazard et al published in Eur $J$ Clin Pharmacol in 2020 reported the lack of evidence on allopurinol use to prevent the first gout attack among persons with asymptomatic hyperuricemia [1]. Some of our ideas are shared with the readers.

In order to support Hazard et al.'s comments, a preliminary case-control study was performed to explore the association between the first gout attack and allopurinol use by analyzing the 2004-2012 database of the Taiwan National Health Insurance Program with covering $99.7 \%$ of 23 million persons living in Taiwan [2]. Persons ages 20 to 84 years who had the first gout attack were assigned as the case group based on International Classification of Diseases, Ninth Revision code. For every person with the first gout attack, 4 sex-matched and age-matched persons without the diagnosis of any gout attack were selected as the control group. Table 1 reveals that the odds of allopurinol use among cases with the first gout attack were significantly higher than the odds of allopurinol use among controls (crude odds ratio $=7.16,95 \%$ confidence interval $=6.11-8.39 ; P<0.001)$. This result indicates that allopurinol use could not prevent the first gout attack. This result partially explains the lack of evidence on allopurinol use to prevent the first gout attack among persons with asymptomatic hyperuricemia [1]. More real-world data are needed to

Shih-Wei Lai

wei@mail.cmuh.org.tw

Kuan-Fu Liao

kuanfuliaog@gmail.com

1 College of Medicine, China Medical University, Taichung, Taiwan

2 Department of Family Medicine, China Medical University Hospital, Taichung, Taiwan

3 Division of Hepatogastroenterology, Department of Internal Medicine, Taichung Tzu Chi Hospital, No.66, Sec. 1, Fongsing Road, Tanzi District, Taichung City 427, Taiwan

4 Department of Research, Taichung Tzu Chi Hospital, Taichung, Taiwan

5 College of Medicine, Tzu Chi University, Hualien, Taiwan explore whether other uric acid-lowing agents can be used to prevent the first gout attack among persons with asymptomatic hyperuricemia.

Table 1 Association between the first gout attack and allopurinol use among persons ages 20-84 in a case-control study from 2004 to 2012

\begin{tabular}{lllll}
\hline & $\begin{array}{l}\text { Cases with the } \\
\text { first gout attack } \\
(n=43,336)\end{array}$ & $\begin{array}{l}\text { Controls } \\
(n=173,344)\end{array}$ & $\begin{array}{l}\text { Crude odds } \\
\text { ratio } \\
(95 \% \mathrm{CI})\end{array}$ & $\begin{array}{l}P \\
\text { value }\end{array}$ \\
\hline $\begin{array}{c}\text { Cumulative duration } \\
\text { of allopurinol use } \\
\geq 3 \text { months }\end{array}$ & 426 & 240 & 7.16 & $<$ \\
$\begin{array}{c}\text { Cumulative duration } \\
\text { of allopurinol use } \\
<3 \text { months }\end{array}$ & $\begin{array}{l}(92910 \\
\text { (99.02) }\end{array}$ & $(0.14)$ & $(6.11-8.39)$ & 0.001 \\
\hline
\end{tabular}

Author contributions Shih-Wei Lai contributed to the conception of the article, initiated the draft of the article, and has approved the final draft submitted.

Yu-Hung Kuo and Kuan-Fu Liao conducted data analysis.

Shih-Wei Lai and Kuan-Fu Liao contributed equally to the article.

\section{Compliance with ethical standards}

Conflict of interest The authors declare that they have no conflict of interest.

\section{References}

1. Hazard A, Bourrion B, Dechaine F, Fournier L, François M (2020) Lack of evidence for allopurinol for the prevention of a first gout attack in asymptomatic hyperuricemia: a systematic review. Eur J Clin Pharmacol 76(6):897-899. https://doi.org/10.1007/s00228020-02849-5

2. Ministry of Health and Welfare Taiwan ([cited on May 1, 2020, English version]) 2018 Taiwan Health and Welfare Report. http:// www.mohw.gov.tw

Publisher's note Springer Nature remains neutral with regard to jurisdictional claims in published maps and institutional affiliations. 